\title{
PERCEPTION OF INFORMATICS STUDENTS ABOUT MATERIALS IN DISKRIT MATHEMATICS USING DOMAIN AND CODOMAIN FUNCTIONS
}

\author{
Dimas Midyan Alam ${ }^{1}$, Alwi Rahmaan ${ }^{2}$ \\ ${ }_{1,2}^{1,}$ Universitas Amikom Yogyakarta \\ 1dimas.0982@students.amikom.ac.id, ${ }^{2}$ alwi.rahmaan@students.amikom.ac.id
}

\begin{abstract}
This study aims to determine the interest of Informatics students about the material in discrete mathematics that is most in demand. The population of this study was 20 students from the Informatics Department at Amikom University Yogyakarta. Data collection techniques using the interview method. The interview method is used to determine student interest in discrete mathematics course material that is in accordance with the actual conditions. In the discussion the author uses functions in discrete mathematics, namely with domain functions, codomain, and range. The results of this study indicate that the interests of Informatics students about matter have discrete mathematics in sufficient categories.
\end{abstract}

Keywords : Learning interest, Lecture material, Function Of Mathematics Discrete, Domain and codomain

\section{PENDAHULUAN}

Pendidikan merupakan kegiatan yang dilakukan dengan sengaja agar peserta didik memiliki sikap dan kepribadian yang baik, serta potensi yang dimiliki dapat digunakan untuk berperan dalam kehidupan bermasyarakat. Salah satu pendidikan pemerintah adalah Universitas Amikom Yogyakarta yang memiliki berbagai macam fakultas dengan menawarkan berbagai jenis jurusan dan program studi yang disesuaikan dengan minat dan bakat calon mahasiswa.

Pelaksanaan perkuliahan yang baik biasanya dipengaruhi dengan adanya mata kuliah yang sesuai kurikulum yang telah ditetapkan. Mata kuliah yang ditawarkan merupakan mata kuliah universitas, mata kuliah fakultas dan mata kuliah program studi. Dimana mata kuliah universitas biasanya wajib diikuti oleh semua mahasiswa dari seluruh program studi yang terdiri dari mata kuliah Agama, Bahasa Inggris, Bahasa Indonesia, Pendidikan Kewarganegaraan, Matematika Dasar.

Pada Matematika Dasar khususnya dalam jurusan Informatika di Universitas Amikom Yogyakarta, Matematika diskrit adalah ilmu paling dasar pada pendidikan informatika atau ilmu komputer. Pada intinya informatika terdiri dari disiplin ilmu dan teknik yang mengolah dan memanipulasi objek diskrit. Oleh karena itu matematika diskrit memberikan landasan matematis untuk kuliahkuliah lain di informatika khususnya di Universitas Amikom Yogyakarta.

Matematika diskrit (discrete mathematics atau finite mathematics) sendiri merupakan cabang matematika yang mengkaji objek-objek diskrit. Matematika diskrit berkembang cepat dalam kurun waktu 10 tahun terakhir ini. alasan yang menyebabkan perkembangannya sangat cepat karena komputer digital bekerja 
secara diskrit. Informasi tersebut dimanipulasi dan disimpan oleh komputer dalam bentuk diskrit.

Berdasarkan uraian di atas, maka permasalahan yang dirumuskan adalah "Materi manakah yang paling diminati mahasiswa Informatika pada mata kuliah Matematika Diskrit?"

Tujuan penelitian adalah Untuk mengidentifikasikan materi mana yang paling diminati mahasiswa Informatika pada mata kuliah Matematika Diskrit.

\section{METODE PENELITIAN}

Penelitian yang dilakukan oleh penulis yaitu memilih mahasiswa jurusan Informatika pada Universitas Amikom Yogyakarta angkatan tahun 2017 sebagai sampel. Data yang digunakan dalam penulisan ini merupakan data primer.

Populasi adalah keseluruhan subjek penelitian dan sampel unit analisis dalam penelitian ini adalah mahasiswa Informatika Universitas Amikom Yogyakarta, angkatan tahun 2017. Penelitian ini direncanakan akan mengambil sampel sebesar 20 orang dan poulasi sebesar 6 materi kuliah pada matematika diskrit yaitu Logika, Himpunan, Matriks, Relasi, Fungsi, Algoritma.

Penelitian yang dilakukan bersifat survei. Survei merupakan penelitian yang mengambil alat pengumpul data yang pokok dan sampel dari suatu populasi. Pengertian survei dibatasi pada survei sampel dimana sebagian populasi diambil untuk mewakili seluruh populasi penelitian (Sugiono, 2006). Desain penelitian (research design) merupakan kerangka kerja atau cetak biru yang bertujuan sebagai pedoman utama dalam melakukan seluruh rangkaian kegiatan penelitian (Sekaran, 2003). Matode yang digunakan adalah metode wawancara dengan melakukan survei menggunakan pendekatan komunikasi verbal secara langsung.

\section{HASIL PENELITIAN DAN PEMBAHASAN}

Pada zaman sekarang ini perkembangan teknologi IT melaju sangat pesat, dalam perkembangannya di imbangi oleh berkembangnya juga matematika diskrit. Semua itu disebabkan karena teknologi digital bekerja secara diskrit atau diskontinyu dan disimpan serta dimanipulasi oleh computer secara diskrit. Matematika diskrit merupakan dasar dalam pendidikan ilmu komputer atau pendidikan informatika. Pada dasarnya informatika merupakan sekumpulan disiplin ilmu dan teknik yang memanipulasi dan mengolah objek-objek diskrit. Pembahasan pada matematika diskrit meliputi beberapa materi dan salah satunya tentang fungsi.

Konsep fungsi sangat penting pada matematika diskrit. Fungsi sering dipakai untuk mentransformasikan elemen di sebuah himpunan dengan elemen di himpunan lain. Definisi fungsi yaitu, diberikan dua himpunan A dan B. Hubungan biner $f$ dari A ke B yaitu salah satu fungsi kalau masing-masing elemen pada $\mathrm{A}$ dihubungkan dengan suatu elemen pada elemen B. misalkan $f$ merupakan fungsi dari A ke B maka, kita menuliskan, $f: \mathrm{A} \rightarrow$ B yang berarti $f$ memetakan A ke B.

Nama lain pada fungsi adalah transformasi atau pemetaan. Kita tuliskan $f$ (a) = b apabila elemen a di A dihubungkan dengan elemen b di B. Himpunan A 
disebut domain dari $f$ dan himpunan B disebut codomain dari $f$. bila $f(\mathrm{a})=\mathrm{b}$, jadi $\mathrm{b}$ disebut image yang berasal dari a dan a dinamakan pra image dari b. Kemudian, sekumpulan yang memuat semua nilai pemetaan $f$ dinamakan range dari $f$.

Fungsi adalah relasi yang khusus. Kekhususan ini tercakup pada dua hal penting yaitu tiap elemen di dalam himpunan $A$, yang merupakan daerah asal $f$, harus digunakan oleh prosedur atau akidah yang mendefinisikan $f$, dan frasa "dihubungkan dengan tepat satu elemen di dalam $B$ " berarti bahwa jika $(a, b) \in f$ dan $(\mathrm{a}, \mathrm{c}) \in f$, maka $\mathrm{b}=\mathrm{c}$. Fungsi dapat dispesifikaikan dalam berbagai bentuk diantaranya yaitu himpunan pasangan berurutan, formula pengisian nilai (assignment), kata-kata, kode program (source code).

Berikut ini data sampel dan populasi yang penulis peroleh untuk penelitian guna menentukan domain dan codomain :

1. Data Kelas Informatika pertama

$\mathrm{A}=\{$ Dimas, Midyan, Alam, Alva, Abi $\}$

$\mathrm{B}=\{$ Logika, Himpunan, Matriks, Relasi, Fungsi, Algoritma $\}$

Domain $=$ Df $=\{$ Dimas, Midyan, Alam, Alva, Abi $\}$

Codomain $=\mathrm{Cf}=$ LLogika, Himpunan, Matriks, Relasi, Fungsi, Algoritma

Range $=\mathrm{Rf}=\{$ Logika, Himpunan, Matriks, Fungsi, Algoritma $\}$

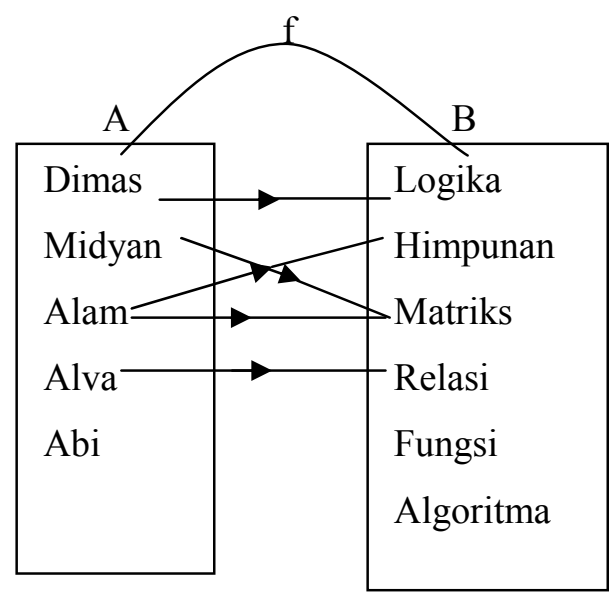

Domain $=$ Df $=\{$ Dimas, Midyan, Alam, Alva, Abi $\}$

Codomain $=\mathrm{Cf}=\{$ Logika, Himpunan, Matriks, Relasi, Fungsi, Algoritma $\}$

Range $=\mathrm{Rf}=\{$ Logika, Himpunan, Matriks, Fungsi, Algoritma $\}$

2. Data Kelas Informatika kedua

$\mathrm{A}=\{$ Ana, Ani, Hasna, Dina, Ita $\}$

$\mathrm{B}=\{$ Logika, Himpunan, Matriks, Relasi, Fungsi, Algoritma $\}$ 


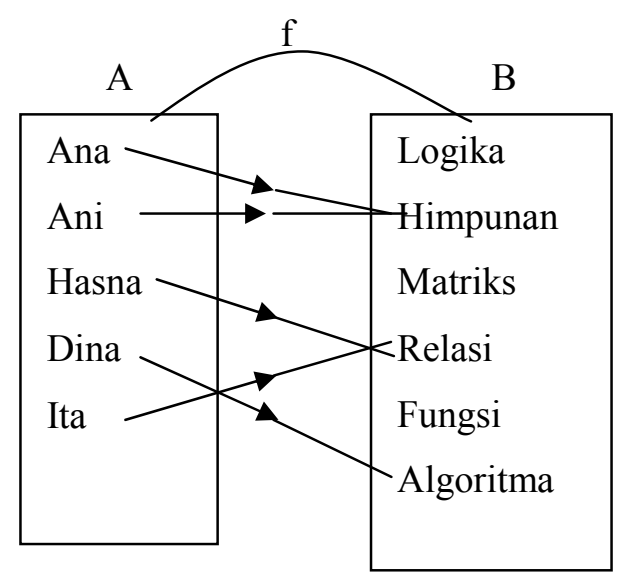

Domain $=$ Df $=\{$ Ana, Ani, Hasna, Dina, Ita $\}$

Codomain $=\mathrm{Cf}=\{$ Logika, Himpunan, Matriks, Relasi, Fungsi, Algoritma $\}$ Range $=\mathrm{Rf}=\{$ Logika, Himpunan, Matriks, Fungsi, Algoritma $\}$

3. Data Kelas Informatika ketiga

$\mathrm{A}=\{$ Ari, Naufal, Adi, Udi, Reza $\}$

$\mathrm{B}=\{$ Logika, Himpunan, Matriks, Relasi, Fungsi, Algoritma $\}$

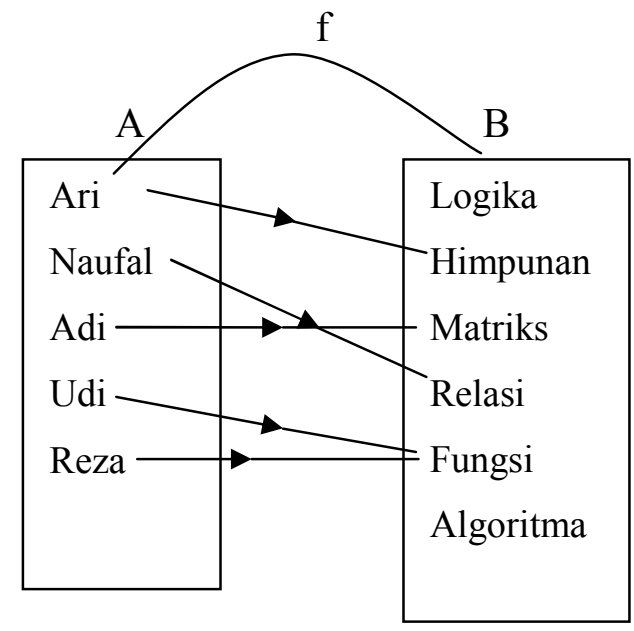

4. Data Kelas Informatika ketiga

$\mathrm{A}=\{$ Dila, Ririn, Eka, Wati, Putri $\}$

$\mathrm{B}=\{$ Logika, Himpunan, Matriks, Relasi, Fungsi, Algoritma $\}$ 


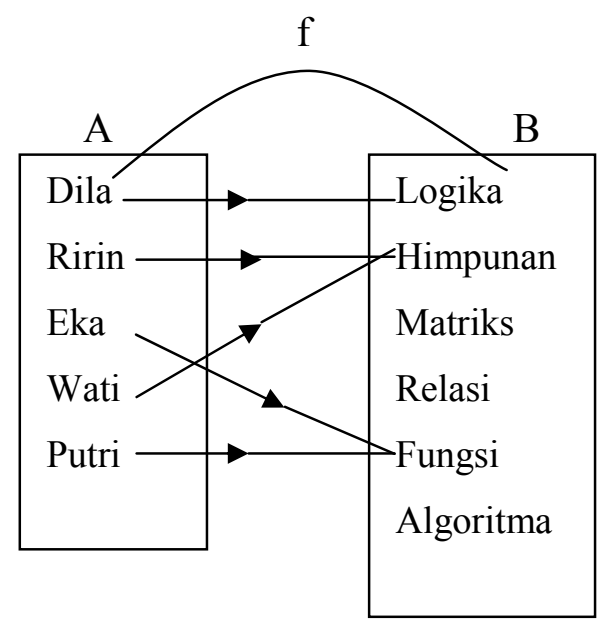

Persentase hasil peminat mata kuliah matematika diskrit adalah sebagai berikut :

Tabel 1. Persentase Sampel Penelitian

\begin{tabular}{|l|c|c|}
\hline \multirow{2}{*}{ Jenis Materi } & Laki-Laki & Perempuan \\
\cline { 2 - 3 } & $(\%)$ & $(\%)$ \\
\hline Logika & $10 \%$ & $10 \%$ \\
\hline Himpunan & $40 \%$ & $20 \%$ \\
\hline Matriks & $10 \%$ & $10 \%$ \\
\hline Relasi & $20 \%$ & $30 \%$ \\
\hline Fungsi & $20 \%$ & $30 \%$ \\
\hline Algoritma & $10 \%$ & $0 \%$ \\
\hline
\end{tabular}

Dari tabel 1, diatas merupakan persentase dari hasil penarikan sampel penilitan terhadap peminat mata kuliah matematika diskrit berdasarkan dari jenis materi mata kuliah tersebut. Penarikan sampel dilakukan berdasarkan dari jenis materi pada mata kuliah matematika diskrit yang meliputi : logika, himpunan, matriks, relasi, fungsi, dan algoritma. Lalu pada penarikan sampel tersebut terdapat perbedaan jenis materi yang diminati pada mata kuliah matematika diskrit antara laki-laki dan perempuan. Dari hasil sampel penelitian untuk lakilaki, lebih banyak peminat pada jenis materi himpunan untuk mata kuliah matematika diskrit. Sedangkan untuk perempuan terdapat dua jenis materi yang diminati karena memiliki hasil yang sama yaitu untuk jenis materi relasi dan fungsi.

\section{SIMPULAN DAN SARAN \\ Simpulan}

Berdasarkan penelitian dan pembahasan data diperoleh kesimpulan bahwa beberapa mahasiswa jurusan Informatika pada Universitas Amikom Yogyakarta yang laki-laki lebih meminati mata kuliah matematika diskrit terutama pada materi Ralasi dan Fungsi, pada materi Relasi dan Fungsi masih kurang yang 
meminati, sedangka untuk materi Logika dan Matriks sangat kurang yang meminati dan pada materi Algoritma tidak ada yang meminati sama sekali.

Sedangkan penelitian untuk beberapa mahasiswa perempuan lebih meminati matematika diskrit terutama pada materi Himpunan, pada materi Relasi dan Fungsi masih kurang yang meminati, dan untuk materi Logika, Matriks, Algoritma sangat kurang yang meminati.

Bisa disimpulkan untuk keseluruhan penelitian bahwa beberapa mahasiswa jurusan Informatika pada Universitas Amikom Yogyakarta paling banyak meminati matematika diskrit terutama pada materi Himpunan dan paling kurang diminati pada materi Algoritma

\section{Saran}

Berdasarkan penelitian yang penulis teliti pada beberapa mahasiswa jurusan Informatika di Universitas Amikom Yogyakarta bahwa pada mata kuliah Matematika Diskrit yang paling diminati oleh beberapa mahasiswa adalah materi Himpunan. Dan untuk buku yang mereka pelajari adalah buku karya dari Rinaldi Munir yang berjudul "Matematika Diskrit” tahun penerbitan 2019.

\section{DAFTAR PUSTAKA}

Munir, Rinaldi, 2009 “Matematika diskrit”. Bandung : Informatika Bandung. Sekaran, Uma, 2003 "Research Methods For Business". Skill-Building Apparoach, Fourth Edition. New York : Jhon Wiley \& nSons Inc.

Siang, Jong Jek, 2009 "Matematika Diskrit dan Aplikasinya pada Ilmu Komputer". Yogyakarta : Andi Offset.

Sugiyono, 2012. "Statistik untuk Penelitian". Bandung : Alfabeta. 